\title{
BMJ Open What is the prevalence, and what are the clinical correlates, of insulin resistance in young people presenting for mental health care? A cross-sectional study
}

\author{
Elizabeth M Scott, ${ }^{1,2}$ Joanne S Carpenter, ${ }^{\circ 1}$ Frank lorfino, ${ }^{\circ}$ Shane P M Cross, ${ }^{1}$ \\ Daniel F Hermens, ${ }^{1,3}$ Jeanne Gehue, ${ }^{1}$ Chloe Wilson, ${ }^{1}$ Django White, ${ }^{1}$ \\ Sharon L Naismith, ${ }^{1}$ Adam J Guastella, ${ }^{1}$ Ian B Hickie ${ }^{1}$
}

To cite: Scott EM, Carpenter JS, Iorfino $\mathrm{F}$, et al. What is the prevalence, and what are the clinical correlates, of insulin resistance in young people presenting for mental health care? A crosssectional study. BMJ Open 2019;9:e025674. doi:10.1136/ bmjopen-2018-025674

- Prepublication history for this paper is available online. To view these files, please visit the journal online (http://dx.doi org/10.1136/bmjopen-2018025674).

Received 8 August 2018 Revised 13 March 2019 Accepted 29 April 2019

Check for updates

(c) Author(s) (or their employer(s)) 2019. Re-use permitted under CC BY-NC. No commercial re-use. See rights and permissions. Published by BMJ.

${ }^{1}$ Brain and Mind Centre, The University of Sydney, Sydney, New South Wales, Australia

${ }^{2}$ School of Medicine, University of Notre Dame, Sydney, NSW,

Australia

${ }^{3}$ Sunshine Coast Mind and Neuroscience Thompson Institute, Birtinya, Queensland, Australia

Correspondence to

Professor lan B Hickie;

ian.hickie@sydney.edu.au

\section{ABSTRACT}

Objectives To report the distribution and predictors of insulin resistance (IR) in young people presenting to primary care-based mental health services.

Design Cross-sectional.

Setting Headspace-linked clinics operated by the Brain and Mind Centre of the University of Sydney.

Participants 768 young people (66\% female, mean age $19.7 \pm 3.5$, range $12-30$ years).

Main outcome measures IR was estimated using the updated homeostatic model assessment (HOMA2IR). Height and weight were collected from direct measurement or self-report for body mass index (BMI). Results For BMI, $20.6 \%$ of the cohort were overweight and $10.2 \%$ were obese. However, $<1 \%$ had an abnormally high fasting blood glucose $(>6.9 \mathrm{mmol} / \mathrm{L})$. By contrast, 9.9\% had a HOMA2-IR score $>2.0$ (suggesting development of IR) and $11.7 \%(n=90)$ had a score between 1.5 and 2. Further, there was a positive correlation between BMI and HOMA2-IR $(r=0.44$, $\mathrm{p}<0.001)$. Participants in the upper third of HOMA2-IR scores are characterised by younger age, higher BMls and depression as a primary diagnosis. HOMA2-IR was predicted by younger age $(\beta=0.19, p<0.001)$ and higher BMI $(\beta=0.49, p<0.001)$, together explaining $22 \%$ of the variance $\left(F_{(2,361)}=52.1, p<0.001\right)$.

Conclusions Emerging IR is evident in a significant subgroup of young people presenting to primary carebased mental health services. While the major modifiable risk factor is BMI, a large proportion of the variance is not accounted for by other demographic, clinical or treatment factors. Given the early emergence of IR, secondary prevention interventions may need to commence prior to the development of full-threshold or major mood or psychotic disorders.

\section{INTRODUCTION}

The shortened life expectancy (in the range of 15-25 years) for those who live with major mental illness is largely driven by premature cardiovascular disease (pCVD). ${ }^{1-3}$ pCVD is particularly notable for those with major depression, bipolar and psychotic
Strengths and limitations of this study

- Observational and cross-sectional study of the distribution of insulin resistance (IR) in a large cohort $(n=768)$ of young people presenting for mental healthcare.

- Cross-sectional evaluation of demographic, clinical (diagnostic, medications) and body mass predictors of IR.

- Uses HOMA2-IR modelling of IR based on fasting insulin and fasting glucose.

- As there is significant heterogeneity in illness type, comorbidity and previous history of illness and medication exposure, the findings are more relevant to similar cohorts presenting to primary care as distinct from older or more diagnostically homogeneous cohorts presenting to secondary or mental health specialist services.

disorders. ${ }^{4} 5$ Explanatory models include behaviourally linked risks (eg, daily tobacco smoking, reduced physical activity, increased sedentary behaviour, poor dietary habits and poor sleeping patterns), ${ }^{6-13}$ reduced access to healthcare $\mathrm{e}^{14}$ and intrinsic central nervous system-driven perturbations of the hypothalamic-pituitary axis, sympathetic nervous system activation and immune-inflammatory systems. ${ }^{16-19}$

Recently, greater emphasis has been placed on the role of metabolic dysfunction in pCVD.$^{20}$ For middle-aged cohorts living with chronic mental illness, the focus is on the longitudinal relationships between weight gain, central obesity and progressive insulin resistance (IR). It is assumed that there is a long lag-time between adolescent-onset of the mental illness (as $75 \%$ of mental disorders commence before age 25 years) secondary weight gain and changes in body fat composition and later onset of metabolic 
dysfunction. ${ }^{162122}$ There is ongoing debate as to the role of exposure to psychotropic medications. ${ }^{23}{ }^{24}$ In particular, second generation antipsychotics have been linked to an increase in a number of severe metabolic abnormalities, ${ }^{425}$ with these effects also being demonstrated in youth. ${ }^{26-28}$ Genetic studies have also identified a potential link between mood disorders and assorted cardiometabolic diseases, suggesting shared biological and pathophysiological mechanism. ${ }^{29}$

In Australia, we now have a variety of different early intervention mental health services that are located at various points along the illness course. Consequently, an important additional goal of these programmes is to improve physical health outcomes and reduce risk factors to pCVD. ${ }^{30}{ }^{31}$ Early psychosis services, and linked at-risk programmes, typically manage clients in their early adult years. By this point, however, high rates of tobacco smoking, being overweight or obese and exposure to psychotropic (antipsychotic and antidepressant) medications, are already common. ${ }^{32}$ Much current work is focused on modifying risks in this subpopulation of young people who are engaged with secondary care or more specialised mental health services. ${ }^{143233}$

Through the development of the headspace programme, however, we now have the opportunity for intervening earlier with a much larger at-risk population. $^{34}$ These services engage younger cohorts (12-25 years) with a broader range of (subthreshold and fullthreshold) anxiety, mood and psychotic syndromes. We have reported that this population also has some significant risk factors for pCVD, notably tobacco smoking, but that it is no more overweight than the general population. ${ }^{35}$ Additionally, rates of increased fasting blood glucose (FBG) are minimal and, at this stage, there is no correlation between increasing body mass index (BMI) and FBG. ${ }^{35}$ The homeostatic model assessment of insulin resistance (HOMA2-IR) is a promising measure to indicate risk for the development of metabolic dysfunction. Previous population-based reference ranges have generally been restricted to either child and adolescent (ie, under 18 years old $)^{36}{ }^{37}$ or adult samples. ${ }^{38-41}$ Suggested cut-offs for metabolic risk in these studies range from 1.2 to 5.2 and do not span the young adult population of interest here. Only one study reports on HOMA-IR in healthy young people (aged 17-24 years), suggesting cut-offs of 2.9 and 2.3 for females and males, respectively. However, it is unclear the extent to which the distribution of IR in young people with mental health problems presenting for care deviates from comparable population-based estimates.

Our earlier findings ${ }^{35}$ led us to suggest that, if we are to intervene early for metabolic dysfunction, we may need to consider alternative measures to BMI and FBG as the most useful tools for identifying individuals at highest risk of metabolic dysfunction or selecting cohorts for secondary prevention interventions. We hypothesised that a significant proportion of young people early in the course of their mental disorder are already developing IR as indicated by raised HOMA2-IR. Further, this perturbation may be predicted by a broader range of demographic, clinical or treatment factors. Consequently, in this report, we describe the distribution of HOMA2-IR in this large headspace-based population and explore predictors of being in the upper third of that distribution.

\section{METHODS}

\section{Cohort selection}

Study participants were drawn from a larger cohort of young people presenting to one of the Brain and Mind Centre's youth mental health clinics that provide an integrated mix of primary-level services branded as headspace. ${ }^{34}{ }^{42}$ These clinics attract young people with subthreshold and full-threshold mental disorders. ${ }^{42}$ Young people have been recruited to a research register for mood, psychotic, developmental and other mental disorders and participated in a systematic surveillance process for assessing risks to metabolic, immune or cardiovascular disease between January 2005 and December 2017. All young people received clinician-based case management and relevant psychological, social and/or medical interventions over the duration of their time in care. Individuals were included in the present study if they (1) were aged between 12 and 30 years of age at the time of initial assessment and (2) agreed to undertake systematic clinical and laboratory screening for metabolic disturbance and risk to cardiovascular disease. Exclusion criteria were (1) lack of capacity to give informed consent (as determined by a psychiatrist), (2) clinically evident intellectual disability and/or insufficient English to participate in the research protocol or (3) current medical treatment for diabetes, thyroid or other active autoimmune disorders. All participants (or their guardians if under 16 years old) gave written informed consent for the use of routinely collected clinical data for research purposes.

As this is a high risk group for the development of metabolic disease, and we have previously shown FBG alone to be insufficient as a screening instrument, ${ }^{35}$ it is standard practice to monitor FBG and insulin in this cohort. Participants were included in this sample if a valid FBG and fasting insulin recording was available. Other clinical and metabolic measures were utilised when available.

\section{Patient and public involvement}

IBH is a member of the National Mental Health Commission, which has direct patient and family membership, and has prioritised a research effort to better inform practice that promotes detection and active management of risk factors to, and development of physical health problems, in patients with mental ill-health. ${ }^{43}$ IBH has also worked extensively with the National Heart Foundation to examine the links between depression and cardiovascular disease and to improve integrated medical and psychiatric care. ${ }^{4-46}$ Our headspace centres have an active patient advisory panel who are consulted with regard to the development and application of research projects 
within our service. This particular work is supported by funding directly from a patient and family foundation, that supports our centre to investigate metabolic, hormonal and other physical health problems in young people with severe mood disorders. The results of the study are provided back directly to our service managers, and through our young persons advisory group, back to the users of our services

\section{Clinical measures}

Primary psychiatric diagnosis was assigned by the referring clinician or a research psychologist. Psychotropic medication use was obtained from clinician report, interview or self-report.

\section{Metabolic measures}

Pathology requests were made by the referring clinician to obtain FBG and fasting insulin values. IR was estimated the updated homeostatic model assessment (HOMA2-IR) using iHOMA2 software V.8.8. ${ }^{47}$ Measures of height and weight were collected from direct measurement or self-report for BMI calculation using the formula: weight $(\mathrm{kg}) \div$ height $(m)^{2}$.

\section{Statistical analysis}

Statistical analyses were performed using the SPSS V.24.0 IBM. Continuous measures are reported as mean $\pm \mathrm{SD}$. Percentages are followed by $\mathrm{n}$ in brackets, that is, \% (n). Between-group comparisons were performed using independent samples t-tests, one-way analysis of variance or $\chi^{2}$ tests where relevant. Pearson's correlations were used to examine associations between continuous variables.

As there are no currently established cut-offs for HOMA2-IR in this population, participants were split into groups based on tertiles of HOMA2-IR for comparisons across clinical, demographic and metabolic measures. In addition, participants were split into groups with HOMA2-IR $<1.5,1.5-2$ and $>2$ to provide approximate comparisons to previously recommended HOMA-IR cut-offs. Multiple linear regression (using the 'enter' method) was used to quantify the relative associations between HOMA2-IR and any variables with significant associations at the univariate level. The following variables were $\log$ transformed prior to analyses to reduce positive skew: age, BMI, fasting glucose, fasting insulin and HOMA2-IR. All analyses were two tailed and employed an $\alpha$ level of 0.05 .

\section{RESULTS}

The key measures of FBG and fasting insulin were available on 768 young people $(66 \%$ female $(n=510)$, mean age $19.7 \pm 3.5$, range $12-30$ years). These were used to calculate HOMA2-IR. For other measures: BMI was available on 364; details of concurrent psychotropic medication on 380; and primary clinical diagnosis on 430.

Those with BMI available were significantly older than those without BMI available (20.1 \pm 3.6 compared with 19.3 \pm 3.3 years old, $\left.\mathrm{t}_{(766)}=2.98, \mathrm{p}=0.003\right)$ but the two groups did not differ on gender distribution, FBG, fasting insulin or HOMA2-IR (all p>0.05). Similarly, those with primary diagnosis information available were significantly older than those without $(20.2 \pm 3.6$ compared with 19.0 \pm 3.2 years old, $\left.\mathrm{t}_{(766)}=4.7, \mathrm{p}<0.001\right)$, and had lower fasting insulin $\left(9.19 \pm 6.29\right.$ vs $9.97 \pm 6.7, \mathrm{t}_{(766)}=2.03$, $\mathrm{p}=0.043$ ) but did not differ on gender distribution, $\mathrm{FBG}$, HOMA2-IR or BMI (all p>0.05). Likewise, those with medication information available were significantly older than those without $(20.1 \pm 3.6$ compared with $19.3 \pm 3.3$ years old, $\mathrm{t}_{(766)}=3.3, \mathrm{p}=0.001$ ) but did not differ on gender distribution, FBG, fasting insulin, HOMA2-IR or BMI (all $\mathrm{p}>0.05$ ).

For BMI, 9.9\% $(\mathrm{n}=36)$ of participants were underweight (defined as $<18.5), 59.3 \% \quad(\mathrm{n}=216)$ were in the normal range, $20.6 \%(\mathrm{n}=75)$ were overweight (defined as $>25)$ and $10.2 \%(\mathrm{n}=37)$ were obese (defined as $>30)$. Less than $1 \%$ of individuals $(\mathrm{n}=6)$ had an abnormally high FBG $(>6.9 \mathrm{mmol} / \mathrm{L})$ and only $1.4 \% \quad(\mathrm{n}=11)$ had FBG in the elevated range $(5.6-6.9 \mathrm{mmol} / \mathrm{L})$. For fasting insulin, 3.4\% ( $\mathrm{n}=26)$ recorded an abnormally high level $(>25 \mathrm{mU} / \mathrm{L})$ and $9.5 \%(\mathrm{n}=73)$ had fasting insulin in the elevated range $(15-25 \mathrm{mU} / \mathrm{L})$. The distribution of HOMA2-IR is shown in figure 1 . Mean HOMA2-IR $( \pm \mathrm{SD})$ was $1.19 \pm 0.80$. A HOMA2-IR score $>2.0$ was found in $9.9 \%(\mathrm{n}=76)$ and a score between 1.5 and 2 was found in $11.7 \%(\mathrm{n}=90)$.

While fasting glucose was higher in males $(4.8 \pm 0.5$ vs $4.6 \pm 0.6$ in females, $\left.\mathrm{t}_{(766)}=4.21, \mathrm{p}<0.001\right)$ no differences were observed between sexes for insulin (males 9.7 \pm 7.2, females $9.5 \pm 6.1, \mathrm{t}_{(766)}=0.46, \mathrm{p}=0.65$ ), HOMA2-IR (males $1.2 \pm 0.9$, females $\left.1.2 \pm 0.8, \mathrm{t}_{(766)}=0.60, \mathrm{p}=0.55\right)$ or $\mathrm{BMI}$ (males 24.1 \pm 5.2 , females 23.5 $\pm 5.4, \mathrm{t}_{(362)}=1.11, \mathrm{p}=0.27$ ). There were small negative correlations between age and fasting insulin $(\mathrm{r}=-0.22, \mathrm{p}<0.001)$ and HOMA2-IR $(\mathrm{r}=-0.21, \mathrm{p}<0.001)$ but no correlation between age and fasting glucose $(\mathrm{r}=0.04, \mathrm{p}=0.337)$. A positive correlation was evident between BMI and age $(\mathrm{r}=0.29, \mathrm{p}<0.001)$. More importantly, there was a positive correlation between BMI and HOMA2-IR ( $\mathrm{r}=0.44, \mathrm{p}<0.001$, see figure 2A), BMI and fasting insulin $(\mathrm{r}=0.43, \mathrm{p}<0.001)$ and $\mathrm{BMI}$ and fasting glucose $(\mathrm{r}=0.11, \mathrm{p}=0.03)$. Comparison of HOMA2-IR between BMI categories found significantly greater IR in those who were obese compared with all other BMI categories and overweight compared with all other BMI categories $\left(\mathrm{F}_{(3,360)}=30.53, \mathrm{p}<0.001\right.$, figure 2B). Differences between normal weight and underweight were not significant. Table 1 reports the proportion, age and sex distribution of individuals in each BMI category that have HOMA2-IR above or below 1.5.

The relationships between HOMA2-IR, split into tertiles and other demographic and clinical variables are shown in table 2. Of interest, those in the upper third of the HOMA2-IR distribution are characterised by younger age, higher BMIs, a lower proportion of persons with anxiety as a primary diagnosis and a higher proportion of persons with depression as a primary diagnosis (but 


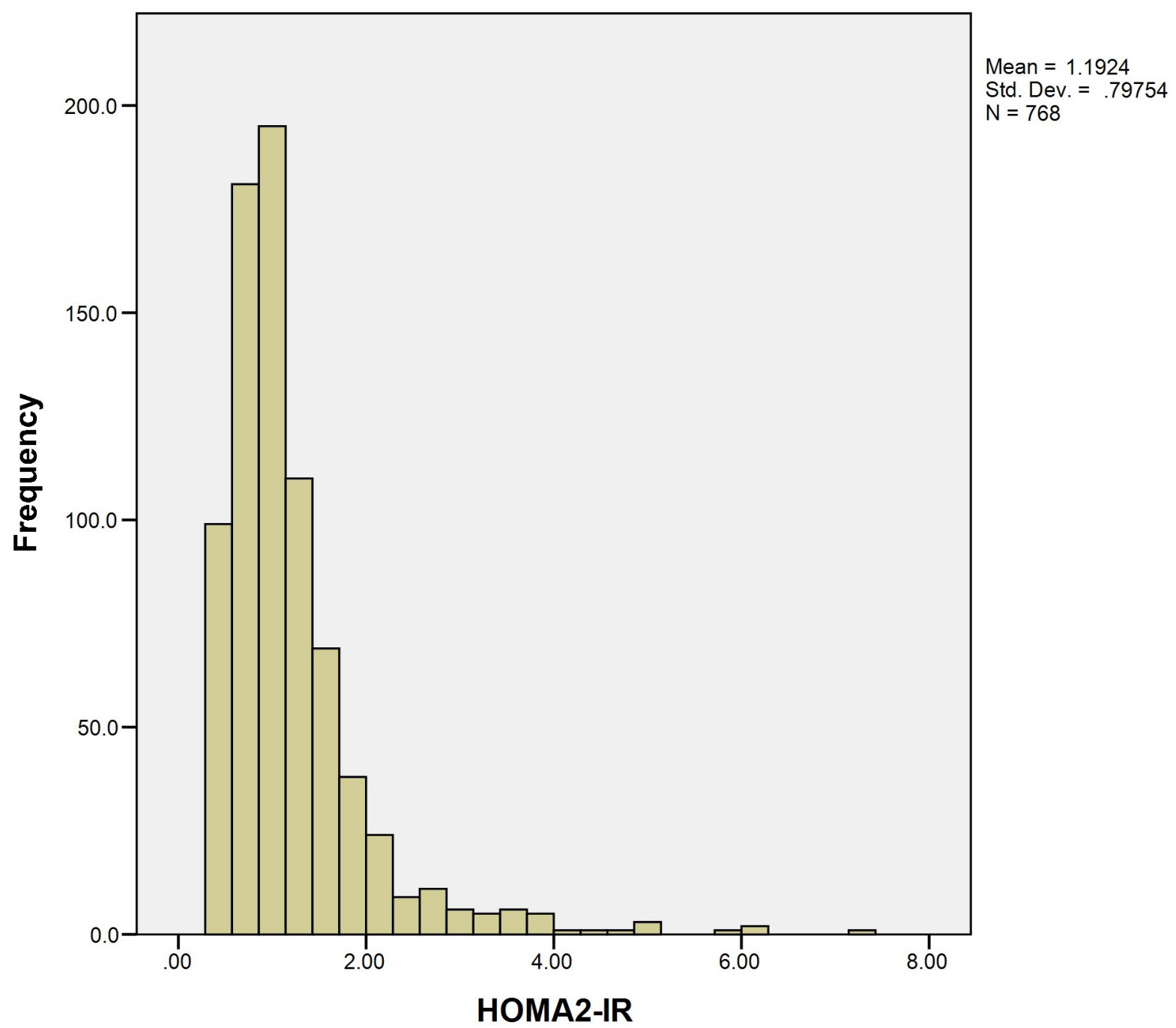

Figure 1 Distribution of HOMA2-IR values. HOMA2-IR, homeostatic model assessment of insulin resistance.

not bipolar or psychotic disorders). There were no clear relationships with specific psychotropic medication use. The overall regression model predicting HOMA2-IR from age and BMI was significant $\left(\mathrm{F}_{(2,361)}=60.55, \mathrm{p}<0.001\right)$ and explained $25 \%$ of the variance in HOMA2-IR. Both younger age $(\beta=-0.27, b=-0.78,95 \%$ CI -1.04 to -0.51 , $\mathrm{p}<0.001)$ and higher BMI $(\beta=0.51, b=1.23,95 \%$ CI 1.04 to $1.51, \mathrm{p}<0.001)$ were significant predictors.

\section{DISCUSSION}

This study of a large number of young people presenting to primary care-based mental health services reports the distribution of HOMA2-IR scores. These individuals present early in the clinical course of a broad admixture of anxiety, depressive, other mood or psychotic disorders and are known to be at high risk of developing metabolic disorders and pCVD. Despite receiving medical and psychological treatments, at this stage of illness the cohort has comparable proportions who are overweight $(21 \%)$ or obese $(10 \%)$ to age-matched controls. In this cohort, $<1 \%$ of individuals had an abnormally high FBG
$(>6.9 \mathrm{mmol} / \mathrm{L})$ and only $1.4 \%$ had FBG in the elevated range $(5.6-6.9 \mathrm{mmol} / \mathrm{L})$. Further, there was no specific correlation between BMI and FBG.

By contrast, using HOMA2-IR as the index measure of developing IR, $10 \%$ have a score $>2$ and $22 \%$ have a score $>1.5$. Independent population-based studies of young people suggest that these ranges indicate being at risk of developing clinically significant IR. ${ }^{37}$ Mean HOMA2-IR in the present study was slightly lower than previous population-based estimates in 18 -year to 19 -year olds ${ }^{48}$ and metabolically healthy 17 -year to 24 -year olds, ${ }^{49}$ as well as adult samples. ${ }^{38-41}$ This indicates that, on average, the young people in the current study are not yet presenting with abnormal IR and associated risk for pCVD. Given the known elevated metabolic risk in this population of young people with mental illness, more research is needed to further elucidate early indicators of metabolic risk.

Consistent with other reports in young people, ${ }^{37}$ there is a significant correlation between BMI and HOMA2-IR $(\mathrm{r}=0.44, \mathrm{p}<0.001)$ in the present study, and HOMA2-IR is best predicted by higher BMI and lower age, together 
A

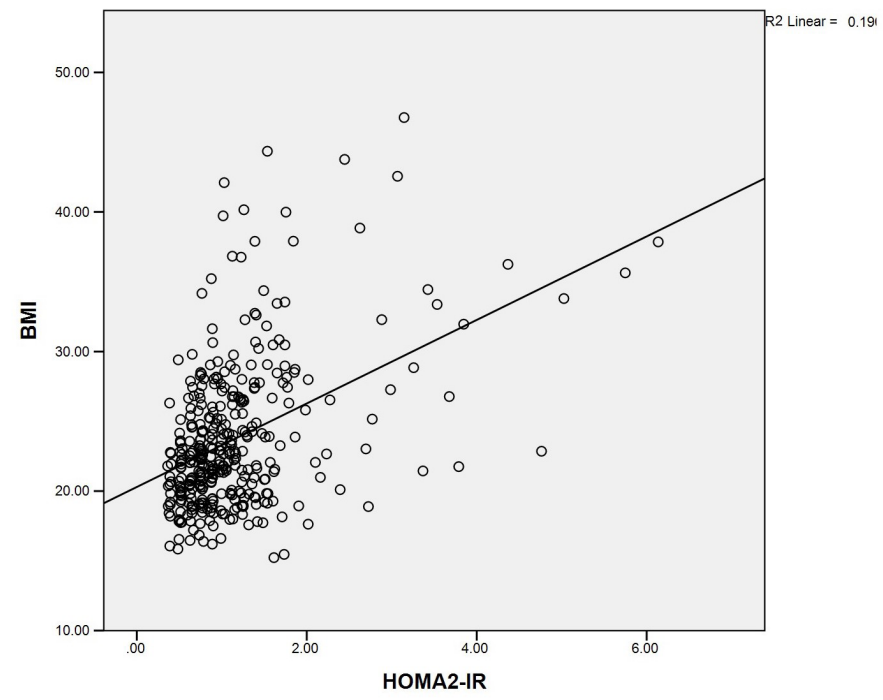

B

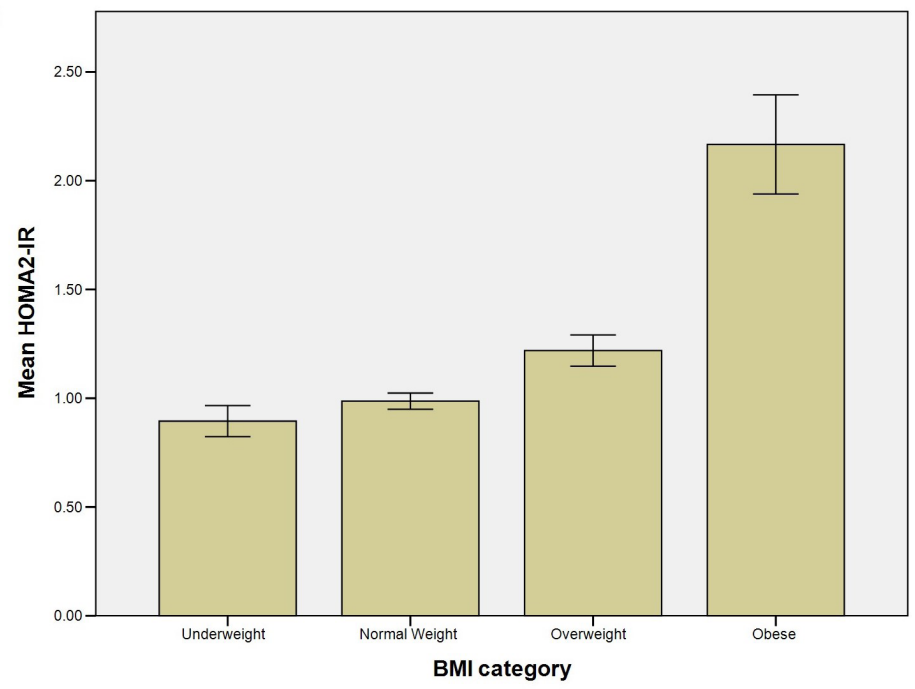

Figure 2 (A) Correlation between BMI and HOMA2-IR. (B) Relationships between HOMA2-IR and BMI categories ( $n=364)$. $\mathrm{BMI}$, body mass index; HOMA2-IR, homeostatic model assessment of insulin resistance.

explaining $25 \%$ of the variance. In this cohort, being in the upper third of HOMA2-IR scores is predicted by higher BMI, younger age and having a primary diagnosis of depression. Reports in older population-based studies have noted associations between depressive symptoms and measures of IR. ${ }^{50}$ Previous research reports a transient increase in IR in early puberty, ${ }^{51} 52$ which may partially explain the association between younger age and IR in the present study.

Notably, being in the upper third of HOMA2-IR is not predicted by specific medication use, including exposure to antidepressant or antipsychotic medications. When interpreting these findings, it is important to consider that drugs of different pharmacological classes (antidepressants, antipsychotics, mood stabilisers and so on) as well as those within the same class are associated with differential degrees of metabolic risk. ${ }^{53}{ }^{54}$ Moreover, comparative to those undergoing pharmacotherapy for extensive periods of time, antipsychotic-naïve and first-episode patients may be more vulnerable to more immediate and aggressive cardiometabolic side effects. ${ }^{55}$ Another possibility is that there are other unexpected relationships between those receiving pharmacotherapy and baseline BMI (eg, reluctance to prescribe specific medications (eg, mirtazapine, olanzapine) in those who are already overweight or obese). Clearly, those who are already overweight or obese may be at increased risk of developing IR if they are subsequently exposed to those

\begin{tabular}{|c|c|c|c|c|}
\hline & Underweight, $\mathrm{n}=36$ & Normal weight, $\mathrm{n}=\mathbf{2 1 6}$ & Overweight, n=75 & Obese, $n=37$ \\
\hline HOMA2-IR < 1.5 (n) & 32 & 192 & 58 & 16 \\
\hline$\%$ of total sample & 9 & 53 & 16 & 4 \\
\hline$\%$ within BMI category & 89 & 89 & 77 & 43 \\
\hline Age $($ mean $\pm S D)$ & $18.7 \pm 3.3$ & $19.8 \pm 3.4$ & $21.4 \pm 3.3$ & $22.6 \pm 3.8$ \\
\hline Sex (\% female) & 91 & 66 & 67 & 75 \\
\hline Potential recommendations & & PWG & WR, IA, AM-IR & WR, IA, AM-IR \\
\hline HOMA2-IR >1.5 (n) & 4 & 24 & 17 & 21 \\
\hline$\%$ of total sample & 1 & 7 & 5 & 6 \\
\hline$\%$ within BMI category & 11 & 11 & 23 & 57 \\
\hline Age $($ mean $\pm S D)$ & $14.8 \pm 1.7$ & $19.2 \pm 3.2$ & $18.7 \pm 3.5$ & $22.6 \pm 4.4$ \\
\hline Sex (\% female) & 50 & 62 & 59 & 57 \\
\hline Potential recommendations & AM-IR & PWG, IA, AM-IR, & WR, IA, AM-IR, & WR, IA, AM-IR, Med \\
\hline
\end{tabular}

Total $\mathrm{n}=364$.

HOMA2-IR, homeostatic model assessment of insulin resistance; AM-IR, annual monitoring of insulin resistance (using HOMA2-IR); IA, increased physical activity; Med, medications, for example, metformin; PWG, prevent wt gain; WR, weight reduction. 
Table 2 Comparison of measures between HOMA2-IR tertiles

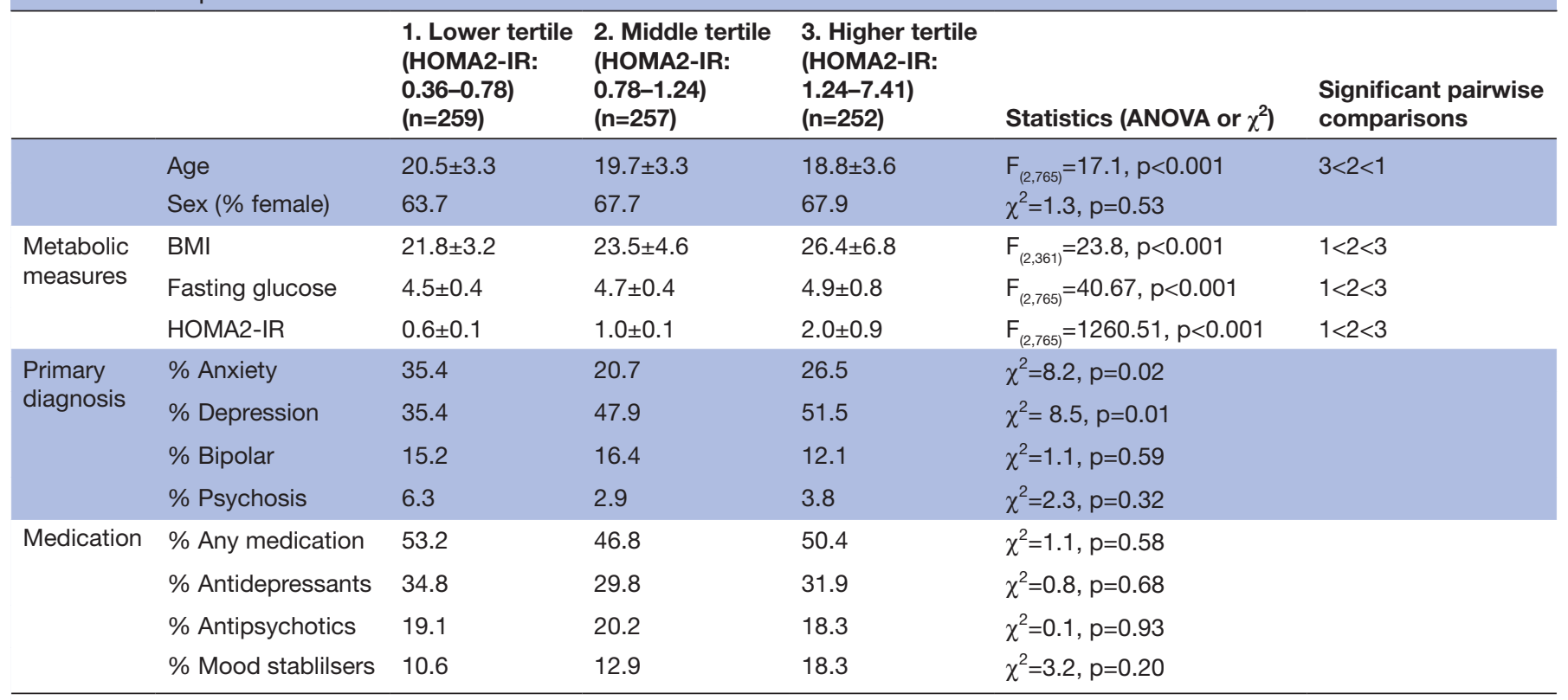

BMI, body mass index; HOMA2-IR, homeostatic model assessment of insulin resistance.

antidepressants or antipsychotics that have been specifically associated with weight gain or rapid onset of IR.

Due to the limitations of the clinical information collected pertaining to specific medication subtypes, doses and duration of medication use; no definitive conclusions pertaining to the effects of specific medications in predicting HOMA2-IR can be drawn from this cross-sectional study.

An important subgroup identified here was those who did not have evidence of IR despite being overweight $(16 \%)$ or obese $(4 \%)$. Other studies suggest that the metabolically healthy but obese individuals may be less sedentary and more physically active, ${ }^{56}$ and may also have a decreased risk of depression over time. ${ }^{57}$ Further higher IR levels have been reported previously in metabolically unhealthy obese individuals. ${ }^{58}$ Our study is consistent with other reports that support the preposition that young overweight individuals are within the relatively early stages of developing metabolic abnormalities, and that this may be detected more readily by abnormal insulin levels at a stage when glucose abnormalities are not yet indicative. ${ }^{59}$

As only $25 \%$ of the variance in HOMA2-IR in this youth mental health cohort is explained by known factors such as body composition and age (and possibly medication exposure in some subgroups), other clinical or pathophysiologcal factors may be contributing to the risk of metabolic disturbance. If we are to develop effective intervention and secondary prevention programmes to reduce the risk of pCVD, and specifically emerging metabolic disturbances, we need to track a direct measure-such as HOMA2-IR - through critical phases of illness onset, persistence and key transitions (such as exposure to psychotropic medications). We also need to explore what other factors may be driving this risk-such as perturbed circadian dysfunction, 24-hour sleep-wake and activity patterns, concurrent inflammatory or immune processes or dietary patterns, independent of specific diagnostic status. ${ }^{1619} 60$

This study is limited by its cross-sectional design which does not allow assessment of longitudinal predictive relationships. In addition, potential selection bias due to the help-seeking nature of participants is likely. While the total sample with fasting insulin and glucose measures was large, additional clinical and metabolic measures were limited by the availability of the data collection method, and a measure of pubertal stage was not available. The results indicate that the sample with these measures was older than those without, which may also bias the findings. However, it should be noted that there were no significant differences between these groups on gender distribution, or fasting insulin and glucose measures.

Current intervention programmes that only measure BMI or FBG, as well as focusing clinical outcome measurement on known risk factors (eg, reducing weight or increasing activity) do not have the capacity to assess effects on emerging IR, and thus it is not known whether such interventions are impacting the emergence of IR. Similarly, the impacts of prescribing specific medications (notably specific antidepressants or antipsychotics) to individuals at risk may well be contributing directly (and quickly) to emerging IR rather than indirectly (and slowly) via weight gain. ${ }^{23}$ Reliance on measures such as BMI or FBG appear to be inadequate means of tracking these changes. However, the optimal choice of objective measures can only be resolved by larger longitudinal cohort, and relevant interventional studies. Future studies would benefit from a longitudinal design and the 
inclusion of additional physical health measures such as smoking status, dietary patterns, inflammatory and immune measures and 24-hour sleep-wake and activity patterns.

Acknowledgements The authors wish to thank Professor Katharine Steinbeck and Professor Stephen Colagiuri for providing expertise on measurement of metabolic risk.

Contributors EMS, IBH, DFH, SLN and AJG designed the study and wrote the protocol. JSC and IBH conducted the statistical analyses. EMS, JSC, CW and IBH interpreted the results and drafted the manuscript. EMS, SPMC, DFH, JG, FI and DW were involved in study coordination and data collection. All authors contributed to and have approved the final manuscript.

Funding This work was partially supported by grants from the National Health and Medical Research Council (NHMRC) including Centre of Research Excellence (No. 1061043), Australia Fellowship (No. 511921 awarded to IBH) and Clinical Research Fellowship (No. 402864 awarded to SLN).

Competing interests EMS is the Medical Director, Young Adult Mental Health Unit, St Vincent's Hospital Darlinghurst, Discipline Leader of Adult Mental Health, School of Medicine, University of Notre Dame, Research Affiliate, The University of Sydney and Consultant Psychiatrist. She has received honoraria for educational seminars related to the clinical management of depressive disorders supported by Servier and Eli-Lilly pharmaceuticals. She has participated in a national advisory board for the antidepressant compound Pristiq, manufactured by Pfizer. She was the National Coordinator of an antidepressant trial sponsored by Servier. IBH has been a Commissioner in Australia's National Mental Health Commission since 2012. He is the Co-director, Health and Policy at the Brain and Mind Centre (BMC) University of Sydney. The BMC operates early intervention youth services at Camperdown under contract to headspace. He has previously led community-based and pharmaceutical industry-supported (Wyeth, Eli Lily, Servier, Pfizer, AstraZeneca) projects focused on the identification and better management of anxiety and depression. He is a Board Member of Psychosis Australia Trust and a member of Veterans Mental Health Clinical Reference group. He was a member of the Medical Advisory Panel for Medibank Private until Oct 2017. He is the Chief Scientific Advisor to, and an equity shareholder in, Innowell. InnoWell has been formed by the University of Sydney and PwC to administer the \$30M Australian Government Funded Project Synergy. Project Synergy is a three year program for the transformation of mental health services through the use of innovative technologies. SLN has received honoraria for an educational seminar for Lundbeck. DFH has received honoraria for educational seminars from JanssenCilag and Eli Lilly.

Patient consent for publication Not required.

Ethics approval The study was approved by the University of Sydney Human Research Ethics Committee.

Provenance and peer review Not commissioned; externally peer reviewed.

Data sharing statement No additional data are available.

Open access This is an open access article distributed in accordance with the Creative Commons Attribution Non Commercial (CC BY-NC 4.0) license, which permits others to distribute, remix, adapt, build upon this work non-commercially, and license their derivative works on different terms, provided the original work is properly cited, appropriate credit is given, any changes made indicated, and the use is non-commercial. See: http://creativecommons.org/licenses/by-nc/4.0/.

\section{REFERENCES}

1. Nordentoft M, Wahlbeck K, Hällgren J, et al. Excess mortality, causes of death and life expectancy in 270,770 patients with recent onset of mental disorders in Denmark, Finland and Sweden. PLoS One 2013;8:e55176.

2. Correll CU, Solmi M, Veronese N, et al. Prevalence, incidence and mortality from cardiovascular disease in patients with pooled and specific severe mental illness: a large-scale meta-analysis of $3,211,768$ patients and $113,383,368$ controls. World Psychiatry 2017; $16: 163-80$.

3. Lawrence D, Hancock KJ, Kisely S. The gap in life expectancy from preventable physical illness in psychiatric patients in Western Australia: retrospective analysis of population based registers. $B M J$ 2013;346:f2539.
4. Vancampfort D, Stubbs B, Mitchell AJ, et al. Risk of metabolic syndrome and its components in people with schizophrenia and related psychotic disorders, bipolar disorder and major depressive disorder: a systematic review and meta-analysis. World Psychiatry 2015;14:339-47.

5. Vancampfort D, Correll CU, Galling B, et al. Diabetes mellitus in people with schizophrenia, bipolar disorder and major depressive disorder: a systematic review and large scale meta-analysis. World Psychiatry 2016;15:166-74.

6. Kilbourne AM, Morden NE, Austin K, et al. Excess heart-diseaserelated mortality in a national study of patients with mental disorders: identifying modifiable risk factors. Gen Hosp Psychiatry 2009;31:555-63.

7. Fleischman A, Lurie I. Cardiovascular mortality and related risk factors among persons with schizophrenia: A review of the published literature. Public Health Rev 2013;34.

8. Vancampfort D, Firth J, Schuch FB, et al. Sedentary behavior and physical activity levels in people with schizophrenia, bipolar disorder and major depressive disorder: a global systematic review and metaanalysis. World Psychiatry 2017;16:308-15.

9. Harvey PD. Cigarette Smoking, Cognitive Performance, and Severe Mental Illness: Quitting Smoking Really Does Seem to Matter. Am J Psychiatry 2018;175:1054-5.

10. Yankey BN, Strasser S, Okosun IS. A cross-sectional analysis of the association between marijuana and cigarette smoking with metabolic syndrome among adults in the United States. Diabetes Metab Syndr 2016;10(2 Suppl 1):S89-S95.

11. Vancampfort D, Firth J, Schuch F, et al. Physical activity and sedentary behavior in people with bipolar disorder: A systematic review and meta-analysis. J Affect Disord 2016;201:145-52.

12. Barandas R, Landgraf D, McCarthy MJ, et al. Circadian Clocks as Modulators of Metabolic Comorbidity in Psychiatric Disorders. Curr Psychiatry Rep 2015;17:98.

13. Matta J, Hoertel N, Kesse-Guyot E, et al. Diet and physical activity in the association between depression and metabolic syndrome: Constances study. J Affect Disord 2019;244:25-32.

14. De Hert M, Cohen D, Bobes J, et al. Physical illness in patients with severe mental disorders. II. Barriers to care, monitoring and treatment guidelines, plus recommendations at the system and individual level. World Psychiatry 2011;10:138-51.

15. Viron MJ, Stern TA. The impact of serious mental illness on health and healthcare. Psychosomatics 2010;51:458-65.

16. Henderson DC, Vincenzi B, Andrea NV, et al. Pathophysiological mechanisms of increased cardiometabolic risk in people with schizophrenia and other severe mental illnesses. Lancet Psychiatry 2015;2:452-64.

17. Lamers F, Vogelzangs N, Merikangas KR, et al. Evidence for a differential role of HPA-axis function, inflammation and metabolic syndrome in melancholic versus atypical depression. Mol Psychiatry 2013;18:692-9.

18. Joseph JJ, Golden SH. Cortisol dysregulation: the bidirectional link between stress, depression, and type 2 diabetes mellitus. Ann N Y Acad Sci 2017;1391:20-34.

19. Hoogendoorn CJ, Roy JF, Gonzalez JS. Shared dysregulation of homeostatic brain-body pathways in depression and Type 2 diabetes. Curr Diab Rep 2017;17:90.

20. Sarwar N, Gao P, Seshasai SR, et al. Diabetes mellitus, fasting blood glucose concentration, and risk of vascular disease: a collaborative meta-analysis of 102 prospective studies. Lancet 2010;375:2215-22.

21. Mottillo S, Filion KB, Genest J, et al. The metabolic syndrome and cardiovascular risk a systematic review and meta-analysis. J Am Coll Cardiol 2010;56:1113-32.

22. Lima L. Subclinical diabetes. An Acad Bras Cienc 2017;89(1 suppl):591-614.

23. Salvi V, Grua I, Cerveri G, et al. The risk of new-onset diabetes in antidepressant users - A systematic review and meta-analysis. PLoS One 2017;12:e0182088.

24. Medici V, McClave SA, Miller KR. Common medications which lead to unintended alterations in weight gain or organ lipotoxicity. Curr Gastroenterol Rep 2016;18:2.

25. Rojo LE, Gaspar PA, Silva H, et al. Metabolic syndrome and obesity among users of second generation antipsychotics: A global challenge for modern psychopharmacology. Pharmacol Res 2015;101:74-85.

26. Correll CU, Manu P, Olshanskiy V, et al. Cardiometabolic risk of second-generation antipsychotic medications during first-time use in children and adolescents. JAMA 2009;302:1765-73.

27. De Hert M, Dobbelaere M, Sheridan EM, et al. Metabolic and endocrine adverse effects of second-generation antipsychotics in children and adolescents: A systematic review of randomized, 
placebo controlled trials and guidelines for clinical practice. Eur Psychiatry 2011;26:144-58.

28. Sjo CP, Stenstrøm AD, Bojesen AB, et al. Development of Metabolic Syndrome in Drug-Naive Adolescents After 12 Months of Second-Generation Antipsychotic Treatment. J Child Adolesc Psychopharmacol 2017;27:884-91.

29. Amare AT, Schubert KO, Klingler-Hoffmann M, et al. The genetic overlap between mood disorders and cardiometabolic diseases: a systematic review of genome wide and candidate gene studies. Transl Psychiatry 2017;7:e1007.

30. Hickie IB. Youth mental health: we know where we are and we can now say where we need to go next. Early Interv Psychiatry 2011;5(Suppl 1):63-9.

31. McGorry P, Bates T, Birchwood M. Designing youth mental health services for the 21st century: examples from Australia, Ireland and the UK. Br J Psychiatry Suppl 2013;54(s54):s30-s35.

32. Galletly CA, Foley DL, Waterreus A, et al. Cardiometabolic risk factors in people with psychotic disorders: The second Australian national survey of psychosis. Aust N Z J Psychiatry 2012;46:753-61.

33. John AP, Koloth R, Dragovic M, et al. Prevalence of metabolic syndrome among Australians with severe mental illness. Med J Aust 2009;190:176-9.

34. McGorry PD, Tanti C, Stokes R, et al. headspace: Australia's National Youth Mental Health Foundation- where young minds come first. Med J Aust 2007;187:S68-S70.

35. Scott EM, Hermens DF, White D, et al. Body mass, cardiovascular risk and metabolic characteristics of young persons presenting for mental healthcare in Sydney, Australia. BMJ Open 2015;5:e007066.

36. Andrade MI, Oliveira JS, Leal VS, et al. [Identification of cutoff points for Homeostatic Model Assessment for Insulin Resistance index in adolescents: systematic review]. Rev Paul Pediatr 2016;34:234-42.

37. Shashaj B, Luciano R, Contoli B, et al. Reference ranges of HOMAIR in normal-weight and obese young Caucasians. Acta Diabetol 2016;53:251-60.

38. Moon S, Park JH, Jang EJ, et al. The Cut-off Values of Surrogate Measures for Insulin Sensitivity in a Healthy Population in Korea according to the Korean National Health and Nutrition Examination Survey (KNHANES) 2007-2010. J Korean Med Sci 2018;33:e197.

39. Motamed N, Miresmail SJ, Rabiee B, et al. Optimal cutoff points for HOMA-IR and QUICKI in the diagnosis of metabolic syndrome and non-alcoholic fatty liver disease: A population based study. $J$ Diabetes Complications 2016;30:269-74.

40. Gayoso-Diz P, Otero-González A, Rodriguez-Alvarez MX, et al. Insulin resistance (HOMA-IR) cut-off values and the metabolic syndrome in a general adult population: effect of gender and age: EPIRCE crosssectional study. BMC Endocr Disord 2013;13:47.

41. Ghasemi A, Tohidi M, Derakhshan A, et al. Cut-off points of homeostasis model assessment of insulin resistance, beta-cell function, and fasting serum insulin to identify future type 2 diabetes: Tehran Lipid and Glucose Study. Acta Diabetol 2015;52:905-15.

42. Scott EM, Hermens DF, Glozier N, et al. Targeted primary carebased mental health services for young Australians. Med J Aust 2012;196:136-40.

43. National Mental Health Commission. Equally Well Consensus Statement: Improving the physical health and wellbeing of people living with mental illness in Australia. Sydney, 2016.
44. Bunker SJ, Colquhoun DM, Esler MD, et al. "Stress" and coronary heart disease: psychosocial risk factors. Med J Aust 2003;178:272-6.

45. Colquhoun DM, Bunker SJ, Clarke DM, et al. Screening, referral and treatment for depression in patients with coronary heart disease. Med J Aust 2013;198:483-4.

46. Glozier N, Tofler GH, Colquhoun DM, et al. Psychosocial risk factors for coronary heart disease. Med J Aust 2013;199:179-80.

47. Hill NR, Levy JC, Matthews DR. Expansion of the homeostasis model assessment of $\beta$-cell function and insulin resistance to enable clinical trial outcome modeling through the interactive adjustment of physiology and treatment effects: iHOMA2. Diabetes Care 2013;36:2324-30.

48. Ata N, Maguire B, Hamilton DC, et al. Percentile curves for cardiometabolic disease markers in Canadian children and youth: a cross-sectional study. BMC Pediatr 2018;18:314.

49. Murguía-Romero M, Jiménez-Flores JR, Méndez-Cruz AR, et al. Insulin and HOMA-IR in Healthy Young Mexicans: A Cut-off Points Proposal. Internal Medicine: Open Access 2014;01(s6).

50. Pyykkönen A-J, Raikkonen K, Tuomi T, et al. and Insulin Resistance: The PPP-Botnia Study. Diabetes Care 2011;34:2545-7.

51. Moran A, Jacobs DR, Steinberger J, et al. Insulin resistance during puberty: results from clamp studies in 357 children. Diabetes 1999;48:2039-44.

52. Jeffery AN, Metcalf BS, Hosking J, et al. Age Before Stage: Insulin Resistance Rises Before the Onset of Puberty. Diabetes Care 2012;41.

53. Hirsch L, Yang J, Bresee L, et al. Second-Generation Antipsychotics and Metabolic Side Effects: A Systematic Review of PopulationBased Studies. Drug Saf 2017;40:771-81.

54. Mangurian C, Newcomer JW, Modlin C, et al. Diabetes and Cardiovascular Care Among People with Severe Mental Illness: A Literature Review. J Gen Intern Med 2016;31:1083-91.

55. Correll CU, Detraux J, De Lepeleire J, et al. Effects of antipsychotics, antidepressants and mood stabilizers on risk for physical diseases in people with schizophrenia, depression and bipolar disorder. World Psychiatry 2015;14:119-36.

56. Cadenas-Sanchez C, Ruiz JR, Labayen I, et al. Prevalence of Metabolically Healthy but Overweight/Obese Phenotype and Its Association With Sedentary Time, Physical Activity, and Fitness. J Adolesc Health 2017;61:107-14.

57. Hinnouho GM, Singh-Manoux A, Gueguen A, et al. Metabolically healthy obesity and depressive symptoms: 16-year follow-up of the Gazel cohort study. PLoS One 2017;12:e0174678.

58. Vukovic R, Milenkovic T, Mitrovic K, et al. Preserved insulin sensitivity predicts metabolically healthy obese phenotype in children and adolescents. Eur J Pediatr 2015;174:1649-55.

59. Abdul-Ghani MA, Tripathy D, DeFronzo RA. Contributions of beta-cell dysfunction and insulin resistance to the pathogenesis of impaired glucose tolerance and impaired fasting glucose. Diabetes Care 2006;29:1130-9.

60. Lamers F, Milaneschi Y, de Jonge P, et al. Metabolic and inflammatory markers: associations with individual depressive symptoms. Psychol Med 2018;48:1-11. 